\section{JURNAL EKONOMI EFEKTIF}

ISSN : $2622-8882$, E-ISSN : 2622-9935

Jurnal Ekonomi Efektif, Vol. 3, No. 1, Oktober 2020 @Prodi Manajemen Fakultas Ekonomi Universitas

Pamulang

\title{
PENGARUH MOTIVASI TERHADAP KINERJA KARYAWAN PADA HANA BANK KANTOR PUSAT JAKARTA
}

\author{
Retno Wulansari \\ Universitas Pamulang \\ dosen00568@unpam.ac.id
}

\begin{abstract}
ABSTRAK
Penelitian ini bertujuan untuk mengetahui pengaruh motivasi terhadap kinerja karyawan pada Hana Bank Kantor Pusat Jakarta. Metode yang digunakan adalah explanatory research dengan sampel sebanyak 85 responden. Teknik analisis menggunakan analisis statistik dengan pengujian regresi, korelasi, determinasi dan uji hipotesis.Hasil penelitian ini variabel motivasi diperoleh rata-rata skor sebesar 3,42 dengan kriteria baik. Variabel kinerja karyawan diperoleh rata-rata skor sebesar 3,84 dengan kriteria baik. Motivasi berpengaruh signifikan terhadap kinerja karyawan dengan persamaan regresi $\mathrm{Y}=8,733+0,866 \mathrm{X}$, dan nilai korelasi 0,783 atau kuat dengan determinasi 61,3\%. Uji hipotesis diperoleh signifikansi $0,000<0,05$.
\end{abstract}

\section{Kata Kunci: Motivasi, Kinerja Karyawan.}

\begin{abstract}
This study aims to determine the effect of motivation on employee performance at Hana Bank Jakarta Head Office. The method used is explanatory research with a sample of 85 respondents. The analysis technique uses statistical analysis with regression testing, correlation, determination and hypothesis testing. The results of this study the motivation variable obtained an average score of 3.42 with good criteria. Employee performance variables obtained an average score of 3.84 with good criteria. Motivation has a significant effect on employee performance with the regression equation $Y=8.733+0.866 X$, and a correlation value of 0.783 or strong with a determination of 61.3\%. Hypothesis testing obtained a significance of $0.000<0.05$.
\end{abstract}

Keywords: Motivation, Employee Performance. 


\section{PENDAHULUAN}

\section{A. Latar Belakang Masalah}

Dalam era globalisasi dimana persaingan perdagangan bebas yang menjadi tantangan baru, sebagai era tanpa batas yang tercermin dengan adanya kebebasan dalam berusaha, kebebasan dalam berpendapat, dan dalam bersaing, praktis tidak ada lagi batas antar satu Negara dengan Negara lain. Era globalisasi adalah kebebasan berusaha yang kemudian dipacu dengan persaingan bebas yang tidak ada lagi batasannya dalam suatu wilayah atau Negara tertentu. Kebebasan berusaha sudah menjadi tuntutan semua masyarakat diseluruh dunia. Keberadaan manajemen SDM sangat penting bagi perusahaan dalam mengelola, mengatur, mengurus dan menggunakan SDM sehingga berfungsi secara efesien, efektif dan produktif merupakan hal yang paling penting untuk mencapai tujuan perusahaan.

Selain itu manajemen juga untuk mencapa suatu tujuan melalui kegiatan orang lain, artinya tujuan dapat dicapai bila dilakukan oleh satu orang atau lebih. Manajemen adalah ilmu dan seni mengatur proses pemanfaatan sumber daya manusia dan sumber sumber lainnya secara efektif dan efesien untuk mencapai suatu tujuan tertentu Hasibuan (2014:2).

Dalam manajemen sumber daya manusia, karyawan adalah kekayaan (asset) utama perusahaan, sehingga harus dipelihara dengan baik. Manajemen SDM menggunakan pendekatan modern dan kajian secara makro. Faktor yang menjadi perhatian dalam manajemen SDM adalah mausianya itu sendiri. Saat ini sangat disadari bahwa SDM merupakan masalah perusahaan yang paling penting karena dengan SDM menyebabkan sumber daya yang lain dalam perusahaan dapat berfungsi atau dijalankan. Melalui SDM yang efektif mengharuskan manajer atau pimpinan dapat menemukan cara terbaik dalam mendayagunakan orang-orang yang ada dalam lingkungan perusahaannya agar tujuantujuan yang diinginkan dapat tercapai.

Adapun manajemen sumber daya manusia menurut Sedarmayanti (2015:13) adalah "Kebijkan dan praktik menentukan asper "manusia" atau sumber daya anusia dalam posisi manajemen termaksud merekrut, menyaring, melatih. Memberi penghargaan dan penilaian". Berhubungan dengan sumber daya manusia yang merupakan perangkat utama atas kelancara aktivitas suatu organisasi dapat berkembang dengan baik, jika tenaga kerja yang berada dalam organisasi dapat berkembang dengan baik, jika tenaga kerja yang berada dalam organisasi tersebut diberikan motivasi terkait dengan tumbuh dan berkembangnya sifat seseorang, sebab motivasi merupakan bagian dalam rangka mendorong karyawan untuk berkerja sesuai tujuan yang telat ditetapkan. Motivasi adalah suatu faktor yang mendorong seseorang untuk melakukan suatu aktivitas tertentu, oleh karena itu motivasi seringkali diartikan pula sebagai faktor pendorong perilaku seorang Edy Sutrisno (2014:109). Pemberian rangsangan yang dapat menimbulkan semangat dan dorongan kerja seoptimal mungkin agar seseorang mau berkerja sama, bekerja secara efektif dan terintegrasi dengan segala upayanya untuk mecapai tujuan organisasi dan memuaskan kebutuhan individu. Besar atau kecilnya pengaruh motivasi kerja tergantung pada seberapa banyaknya intensitas motivasi yang diberikan, melalui tanggung jawab dalam melakukan pekerjaab, prestasi yang dicapainya, pengembangan diri, serta kemandirian dalam bertindak. Motivasi adalah sikap hormat terhadap peraturan dan ketetapan perusahaan, yang ada dalam diri karyawan, yang menyebabkan menyesuaikan diri dengan sukarela pada peraturan dan ketetapan perusahaan Edy Sutrisno (2016:87).

Motivasi harus ditegakan dalam organisasi perusahaan. Tanpa dukungan motivasi karyawan yang baik, sulit perusahaan untuk mewujudkan tujuannya. Jadi, kemotivasian adalah kunci keberhasilan suatu perusahaan dalam mencapai tujuannnya. 
Kinerja kerja adalah hasil kerja secara kualitas dan kuantitas yang dicapai oleh seorang kinerja karyawan dalam melaksanakan tugasnya sesuai dengan tanggung jawab yang diberkan kepadanya Anwar Prabu Mangkunegara (2013:67). Dari pengertian kinerja tersebut maka kinerja kerja karyawan berarti prestasi atau kontribusi yang diberikan oleh karyawan dalam melaksanakan tugas dan tanggung jawab serta fungsinya sebagai karyawan perusahaan. Kinerka kerja dapat dicapai dengan mengandalkan kemampuan intelektual, emosional, dan spiritual serta ketahanaan diri dalam menghadapi situasi segala aspek kehidupan.

Hana Bank dalam usaha pencapaian tujuanya mengharapkan seluruh karyawan mampu menjalankan tugas-tugasnya dengan baik. Keinginan tersebut dapat dicapai bila karyawan memiliki motivasi kerja yang tinggi karna apabila tidak ada motivasi kerja, seorang tidak akan mencapai yang diharapkan walupun landasan oleh kemampuan dan pengalaman, karena motivasi kerjda dapat mempengaruhi kualitas out put tersebut.

Berdasarkan observasi masih banyak karyawan tidak motivasi dalam hal absensi kehadiran dikarenakan tidak adanya tindakan tegas dari pemimpin terhadap karyawan yang melangar peraturan.

Sementara itu dari segi kinerja kerja karyawan terdapat permasalahan mendasar yang penulis temukan yaitu kurangnya kemampuan karyawan dalam menjalankan standar yang ditentukan oleh atasannya, minimnya alat atau sarana yang diberikan atasan dalam menunjang kinerja kerja karyawan, terdapat karyawan yang tidak berkompetensi dibidangnya mengakibatkan penurunan kinerja kerjanya.

Berdasarkan uraian di atas, maka penulis tertarik melakukan penelitian dengan judul: "Pengaruh Motivasi Terhadap Kinerja Karyawan Pada Hana Bank Kantor Pusat Jakarta ".

\section{B. Rumusan Masalah}

1. Bagaimana motivasi pada pada Hana Bank Kantor Pusat Jakarta?.

2. Bagaimana kinerja karyawan pada Hana Bank Kantor Pusat Jakarta ?.

3. Adakah pengaruh antara motivasi terhadap kinerja karyawan pada Hana Bank Kantor Pusat Jakarta?.

\section{Tujuan Penelitian}

1. Untuk mengetahui kondisi motivasi pada Hana Bank Kantor Pusat Jakarta ?.

2. Untuk mengetahui kondisi kinerja karyawan pada Hana Bank Kantor Pusat Jakarta ?.

3. Untuk mengetahui pengaruh antara motivasi terhadap kinerja karyawan pada Hana Bank Kantor Pusat Jakarta?.

\section{METODE PENELITIAN}

\section{Populasi}

Populasi dalam penelitian ini berjumlah 85 responden Hana Bank Kantor Pusat Jakarta

\section{Sampel}

Teknik pengambilan sampling dalam penelitian ini adalah samplel jenuh, dimana semua anggota populasi dijasikan sebagai sampel. Dengan demikian sampel dalam penelitian ini berjumlah 85 responden.

\section{Jenis Penelitian}

Jenis penelitian yang dipakai adalah asosiatif, dimana tujuannya adalah untuk mengetahui mencari keterhubungan antara variabel independen terhadap variabel dependennya 


\section{Metode Analisis Data}

Dalam menganalisis data digunakan uji validitas, uji reliabilitas, analisis regresi linier sederhana, koefisien korelasi, koefisien determinasi dan uji hipotesis.

\section{HASIL PENELITIAN DAN PEMBAHASAN}

\section{Analisis Deskriptif}

Pada pengujian ini digunakan untuk mengetahui skor minimum dan maksimum skor tertinggi, ratting score dan standar deviasi dari masing-masing variabel. Adapun hasilnya sebagai berikut:

\section{Tabel 1. Hasil Analisis Descriptive Statistics}

\section{Descriptive Statistics}

\begin{tabular}{|l|r|r|r|r|r} 
& N & Minimum & Maximum & Mean & \multicolumn{1}{c}{ Std. Deviation } \\
\hline Motivasi (X) & 96 & 28 & 44 & 34.20 & 3.810 \\
\hline Kinerja Karyawan (Y) & 96 & 29 & 49 & 38.36 & 4.218 \\
\hline Valid N (listwise) & 96 & & & & \\
\hline
\end{tabular}

Motivasi diperoleh varians minimum sebesar 28 dan varians maximum 44 dengan ratting score sebesar 3,42 dengan standar deviasi 3,810.

Kinerja karyawan diperoleh varians minimum sebesar 29 dan varians maximum 49 dengan ratting score sebesar 3,84 dengan standar deviasi 4,218.

\section{Analisis Verifikatif.}

Pada analisis ini dimaksudkan untuk mengetahui pengaruh variabel independen terhadap variabel dependen. Adapun hasil pengujian sebagai berikut:

\section{a. Analisis Regresi Linier Sederhana}

Uji regresi ini dimaksudkan untuk mengetahui perubahan variabel dependen jika variabel independen mengalami perubahan. Adapun hasil pengujiannya sebagai berikut:

Tabel 2. Hasil Pengujian Regresi Linier Sederhana Coefficients $^{\mathrm{a}}$

\begin{tabular}{|c|c|c|c|c|c|}
\hline \multirow[b]{3}{*}{ Model } & \multicolumn{2}{|c|}{ Coemincients } & \multirow[b]{2}{*}{$\begin{array}{l}\text { Standardized } \\
\text { Coefficients }\end{array}$} & \multirow[b]{3}{*}{$\mathrm{t}$} & \multirow[b]{3}{*}{ Sig. } \\
\hline & $\begin{array}{l}\text { Unsta } \\
\text { Co€ }\end{array}$ & $\begin{array}{l}\text { Idardized } \\
\text { ficients }\end{array}$ & & & \\
\hline & B & Std. Error & Beta & & \\
\hline 1 (Constant) & 8.733 & 2.445 & & 3.572 & .001 \\
\hline Motivasi (X) & .866 & .071 & .783 & 12.193 & .000 \\
\hline
\end{tabular}

a. Dependent Variable: Kinerja karyawan $(\mathrm{Y})$

Berdasarkan hasil pengujian pada tabel di atas, diperoleh persamaan regresi $\mathrm{Y}$ $=8,733+0,866 \mathrm{X}$. Dari persamaan tersebut dijelaskan sebagai berikut:

1) Konstanta sebesar 8,733 diartikan jika motivasi dan motivasi tidak ada, maka telah terdapat nilai kinerja karyawan sebesar 8,733 point.

2) Koefisien regresi motivasi sebesar 0,866 , angka ini positif artinya setiap ada peningkatan motivasi sebesar 0,866 maka kinerja karyawan juga akan mengalami peningkatan sebesar 0,866 point.

\section{b. Analisis Koefisien Korelasi}

Analisis koefisien korelasi dimaksudkan untuk mengetahui tingkt kekuatan hubungan dari variabel independen terhadap variabel dependen baik secara parsial maupun simultan. Adapun hasil pengujian sebagai berikut: 
Tabel 3. Hasil Pengujian Koefisien Korelasi Motivasi Terhadap Kinerja karyawan. Correlations $^{\text {b }}$

\begin{tabular}{llr|r} 
& & Motivasi $(\mathrm{X} 1)$ & \multicolumn{2}{c}{$\begin{array}{c}\text { Kinerja karyawan } \\
(\mathrm{Y})\end{array}$} \\
\hline Motivasi $(\mathrm{X})$ & Pearson Correlation & 1 & $.783^{* *}$ \\
\cline { 2 - 4 } & Sig. (2-tailed) & & .000 \\
\hline Kinerja Karyawan $(\mathrm{Y})$ & Pearson Correlation & $.783^{* *}$ & 1 \\
\cline { 2 - 4 } & Sig. (2-tailed) & .000 & \\
\hline
\end{tabular}

**. Correlation is significant at the 0.01 level (2-tailed).

b. Listwise $\mathrm{N}=96$

Berdasarkan hasil pengujian diperoleh nilai korelasi sebesar 0,783 artinya motivasi memiliki hubungan yang kuat terhadap kinerja karyawan.

\section{c. Analisis Koefisien Determinasi}

Analisis koefisien determinasi dimaksudkan untuk mengetahui besarnya persentase pengaruh dari variabel independen terhadap variabel dependen. Adapun hasil pengujian sebagai berikut:

Tabel 4. Hasil Pengujian Koefisien Determinasi Motivasi Terhadap Kinerja karyawan.

Model Summary

\begin{tabular}{|c|c|c|c|c|}
\hline \multicolumn{5}{|c|}{ 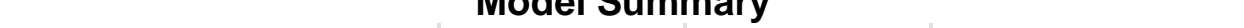 } \\
\hline Model & $\mathrm{R}$ & R Square & $\begin{array}{l}\text { Adjusted R } \\
\text { Square }\end{array}$ & $\begin{array}{l}\text { Std. Error of the } \\
\text { Estimate }\end{array}$ \\
\hline 1 & $.783^{a}$ & .613 & .609 & 2.639 \\
\hline
\end{tabular}

a. Predictors: (Constant), Motivasi (X1)

Berdasarkan hasil pengujian diperoleh nilai determinasi sebesar 0,613 artinya motivasi memiliki kontribusi pengaruh sebesar $61,3 \%$ terhadap kinerja karyawan.

\section{d. Uji Hipotesis}

Pengujian hipotesis dengan uji t digunakan untuk mengetahui hipotesis mana yang diterima.

Rumusan hipotesis: Terdapat pengaruh yang signifikan antara motivasi terhadap kinerja karyawan.

Tabel 5. Hasil Uji Hipotesis Motivasi Terhadap Kinerja karyawan. Coefficients $^{a}$

Unstandardized

Coefficients

\begin{tabular}{|c|c|c|c|c|c|c|}
\hline \multirow{2}{*}{\multicolumn{2}{|c|}{ Model }} & \multicolumn{2}{|c|}{ Coefficients } & \multirow{2}{*}{$\begin{array}{c}\text { Coefficients } \\
\text { Beta }\end{array}$} & \multirow[b]{2}{*}{$\mathrm{t}$} & \multirow[b]{2}{*}{ Sig. } \\
\hline & & $\mathrm{B}$ & Std. Error & & & \\
\hline 1 & (Constant) & 8.733 & 2.445 & & 3.572 & .001 \\
\hline & Motivasi (X) & .866 & .071 & .783 & 12.193 & .000 \\
\hline
\end{tabular}

a. Dependent Variable: Kinerja Karyawan $(\mathrm{Y})$

Berdasarkan hasil pengujian pada tabel di atas, diperoleh nilai t hitung $>\mathrm{t}$ tabel atau $(12,193>1,986)$, dengan demikian hipotesis yang diajukan bahwa terdapat pengaruh yang signifikan atara motivasi terhadap kinerja karyawan diterima.

\section{PEMBAHASAN HASIL PENELITIAN}

\section{Kondisi Jawaban Responden Variabel Motivasi}

Berdasarkan jawaban responden, variabel motivasi diperoleh ratting score sebesar 3,42 berada di rentang skala 3,40-4,19 dengan kriteria baik atau setuju.

\section{Kondisi Jawaban Responden Variabel Kinerja karyawan}

Berdasarkan jawaban responden, variabel kinerja karyawan diperoleh ratting score sebesar 3,84 berada di rentang skala 3,40 - 4,19 dengan kriteria baik atau setuju. 


\section{Pengaruh Motivasi Terhadap Kinerja karyawan}

Motivasi berpengaruh signifikan terhadap kinerja karyawan dengan persamaan regresi $\mathrm{Y}=17,517+0,565 \mathrm{X}$, nilai korelasi sebesar 0,783 atau memiliki hubungan yang kuat dengan kontribusi pengaruh sebesar $61,3 \%$. Pengujian hipotesis diperoleh nilai $t$ hitung > t tabel atau $(12,193>1,986)$. Dengan demikian hipotesis yang diajukan bahwa terdapat berpengaruh signifikan antara motivasi terhadap kinerja karyawan diterima.

\section{PENUTUP}

\section{Kesimpulan}

a. Variabel motivasi diperoleh ratting score sebesar 3,42 berada di rentang skala 3,404,19 dengan kriteria baik atau setuju.

b. Variabel kinerja karyawan diperoleh ratting score sebesar 3,84 berada di rentang skala 3,40 - 4,19 dengan kriteria baik atau setuju.

c. Motivasi berpengaruh signifikan terhadap kinerja karyawan dengan persamaan regresi $\mathrm{Y}=17,517+0,565 \mathrm{X}$, nilai korelasi sebesar 0,783 atau kuat dan kontribusi pengaruh sebesar $61,3 \%$ sedangkan sisanya sebesar $57,9 \%$ dipengaruhi faktor lain. Uji hipotesis diperoleh nilai $\mathrm{t}$ hitung $>\mathrm{t}$ tabel atau $(12,193>1,986)$.

\section{Saran}

a. Perusahaan harus menegakkan peraturan dengan baik sesuai dengan ketentuan yang berlaku guna menjamin kinerja karyawan diperlakukan dengan adil.

b. Perusahaan harus selalu memberikan semangat dan apresiasi yang layak untuk memastikan kinerja karyawan memiliki semangat kerja yang tinggi.

c. Kinerja perusahaan dapat ditingkatkan dengan memberdayakan kinerja karyawan dengan menegakkan peraturan yang baik dan pemberian motivasi yang lebih inten lagi.

\section{DAFTAR PUSTAKA}

Abdullah, M (2014) Manajemen dan Evaluasi Kinerja Karyawan, Yogyakarta: Penerbit Aswaja Pressindo.

Dessler, G. (2006.) Manajemen Sumber Daya Manusia (Jilid II). Jakarta: Indeks.

George Terry R \& Rue, Leslie W. Rue (2016) Dasar-Dasar Manajemen, Jakarta Bumi Aksara.

Gerry Dessler (2016) Human Resources Management, Prenticehall, London: International Inc.

Hasibuan, Malayu S.P. (2016). Manajemen Sumber Daya Manusia. Edisi Revisi. Jakarta: PT Bumi Aksara.

Imam Ghozali (2017). “Aplikasi Analisis Multivariate Dengan Program SPSS”. Edisi Kelima. Semarang: Badan Penerbit Undip.

Istijanto (2014) “Riset Sumber Daya Manusia”. Jakarta: PT. Gramedia Pustaka

Jasmani, J., \& Paeno, P. (2019). The Effect of Leadership and Competence on Lecturer Performance and Its Implications on Student Learning Motivation at Pamulang University. International Journal of Advances in Social and Economics, 1(4).

Luthans Fred (2014) Organizational Behavior, Ney York: McGraw-Hill, New York.

Mangkunegara, Prabu Anwar. (2016). Evaluasi Kinerja SDM. Cetakan ke tujuh, PT Refika Aditama: Bandung.

Pranoto, P., Jasmani, J., \& Marayasa, I. N. (2019). Pelatihan Digital Marketing Untuk Peningkatan Perekonomian Anggota Karang Taruna Al Barkah Di Kampung Cicayur-Tangerang. Jurnal Pengabdian Dharma Laksana, 1(2), 250-258. 
Prasada, D., Sunarsi, D., \& Teriyan, A. (2020). Pengaruh Etos Kerja Dan Kompensasi Terhadap Komitmen Organisasi Pada DHL Logistic Di Jakarta. JENIUS (Jurnal Ilmiah Manajemen Sumber Daya Manusia), 4(1), 51-60.

Robbins, P.S, \& Judge, A.T. (2003). Organizational Behavior. Jakarta: Salemba Empat. Sugiyono (2017), "Metode Penelitian Administrasi : dilengkapi dengan Metode $R \&$ D". Bandung: Alfabeta.

Sunarsi, D. (2018). Buku Ajar: Seminar Perencanaan Sumber Daya Manusia. Tangerang Selatan: Asmoro Mediatama

Sunarsi, D. (2018). Pengembangan Sumber Daya Manusia Strategik \& Karakterisrik Sistem Pendukungnya : Sebuah Tinjauan. Jurnal Ilmiah MEA (Manajemen, Ekonomi, \& Akuntansi), 2(3), 178 - 194

Veithzal Rivai (2015) Manajemen Sumber Daya Manusia Untuk Perusahaan, Jakarta: Raja Grafindo Persada.

Wibowo (2015) Manajemen Kinerja, Jakarta: PT. Raja Grafindo Persada

Yuangga, K. D., \& Sunarsi, D. (2018). The Influence of Procrastination and Low Time Management on Student Self Efficacy (at MA Soebono Mantofani). PINISI Discretion Review, 2(1), 85-92. 